IRA-International Journal of Technology \& Engineering ISSN 2455-4480

Proceedings of the

International Conference on Science \& Engineering for Sustainable Development(2017)

Pg. no. 11-18

Published by: Institute of Research Advances https://research-advances.org/index.php/IRAJTE

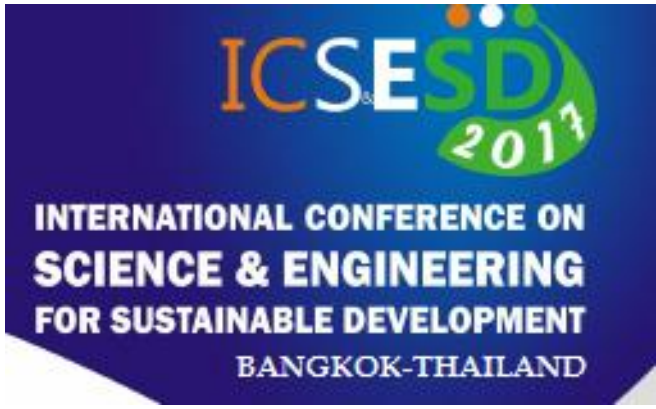

\title{
Comparison of Computational Fluid Dynamics and Experimental Power Output of a Micro Horizontal-Axis Wind Turbine
}

\author{
Sanjay D. Nikhade ${ }^{* 1}$, SuhasC.Kongre ${ }^{2}$, S.B. Thakre $^{3}$, S.S Khandare ${ }^{4}$ \\ ${ }^{1}$ Asst. Professor,Dr..D Y Patil School of Engineering \& Technology, (Charholibk), Pune, \\ India. (sanjaynikhade@ rediffmail.com) \\ ${ }^{2}$ Sr.Lecturer, ASP, Pipari, Wardha ,India. (suhas_kongre@ rediffmail.com) \\ ${ }^{3}$ Professor,Prof.RamMeghe Institute of Technology \& Research, Badnera, Amravati, \\ India.(sbthakre2007@gmail.com) \\ ${ }^{4}$ Ex. Principal, B. D. College of Engineering, Wardha,India. \\ (shashikhan_ngp@hotmail.com)
}

Type of Review: Originality Check \& Peer Review under the responsibility of the Scientific Committee of the Conference and The Institution of Engineers (India).

DOI: http://dx.doi.org/10.21013/jte.ICSESD201702

\section{How to cite this paper:}

Nikhade, S., Kongre, S., Thakre, S., Khandare, S. (2017). Comparison of Computational Fluid Dynamics and Experimental Power Output of a Micro Horizontal-Axis Wind Turbine. Proceedings of the International Conference on Science \& Engineering for Sustainable Development (2017), 11-18. doi:http://dx.doi.org/10.21013/ite.ICSESD201702

(C) International Conference on Science \& Engineering for Sustainable Development\& The Institution of Engineers (India).

\section{$(\mathrm{oc})$ EY-NC}

This work is licensed under a Creative Commons Attribution-Non Commercial 4.0 International License subject to proper citation to the publication source of the work.

Disclaimer: The conference papers as published by the Institute of Research Advances (IRA) are the views and opinions of their respective authors and are not the views or opinions of the IRA. The IRA disclaims of any harm or loss caused due to the published content to any party. 


\section{ABSTRACT}

This paper presents a combined experimental and Computational Fluid Dynamics (CFD) simulation of Micro wind Turbine with 2.28 meters rotor Diameter is performed using the FLUENT 16.2 WORKBENCH. A Micro Horizontal Axis Three Blade Wind Turbine was designed, developed and tested for power performance on new airfoil AFN2016 Designed. The three blades were fabricated from glass fiber with a rotor swept area of 3.14 sq.m for the 1-meter length of the blade and angle of attack experimentally determined to be $5^{\circ}$.The blade is designed for tip speed ratio (TSR) of 7. The power out measured for wind speed from $3.0 \mathrm{~m} / \mathrm{s}$ to $9.0 \mathrm{~m} / \mathrm{s}$. The comparison of the CFD and experimental results on the relationship between the power obtained and the wind speed of the wind turbine at the wind from 3-9 $\mathrm{m} / \mathrm{s}$. It can be clearly seen that the experimental data match quite well again with the numerical analysis and they both demonstrated that the power of wind turbine increasing with wind speed increases.

Keywords: Micro Wind turbines, Aerodynamics, Computational Fluid Dynamics (CFD),Blades, Wind turbines, Rotors, Aerodynamics, Wind speed, Wind energy, Torque

\section{Introduction}

Small wind turbine industry is forecasted to grow at a satisfactory rate compared to the past because of many reasons such as government policies, increasing awareness about renewable energy, research and development in the computational and manufacturing technologies. Hence it is need of an hour to develop new Micro Wind Turbine to be operated at low speeds. For harnessing wind energy, Micro Wind Turbines are best suited for both urban and rural areas. The blade of wind turbine plays the important role to convert wind energy efficiently into mechanical energy and to capture wind energy. The energy captured by rotor depends on the wind air density and the swept area of the rotor.By increasing the efficiency of a wind turbine, then more power can be generated, the Turbine power generation depends on the interaction between the turbine rotor and the wind speed. The efficiency of the blade is mainly depending on the airfoil. [9]. At low Reynolds number computational simulation of the aerodynamic behavior of Micro Wind Turbine depends on the flow field around a wind turbine blade.To improve the performance of Micro Wind Turbine accurate aerodynamic characteristics to be obtained forbetter design.

While performing wind tunnel experiments cost is the main factor for predicting the aerodynamic behavior of a wind turbine using Computational Fluid Dynamics (CFD) became a Economical solution. This study focused on the comparison of the power output of Horizontal Axis Micro Wind Turbine using computational simulation and experimental results .[1,2,3]

\section{MICRO WIND TURBINES}

Many Research has been carried out to design the wind turbine blade for achieving efficient Aerodynamic shapes as the blade is important part of wind Turbine. Blades are manufactured commercially depends on the available wind energy and the final requirement in various sizes for extracting sufficient energy from available wind.

Power developed by wind turbine depends upon wind velocity and swept area is expressed as follows in equation 1

$$
P=\frac{1}{2} \rho A V^{2}
$$

$\rho$ is Air density, $\mathrm{V}$ is Velocity of the wind $(\mathrm{m} / \mathrm{s})$ and A is Area $\left(\mathrm{m}^{2}\right)$. 
According to Betz limit. Maximum power produce by a turbine rotor is $0.59 \%$ or $16 / 27$ from available total power and is expressed as follows in equation 2.

$$
P=\left(\frac{16}{27}\right) \frac{1}{2} \rho A V^{3}
$$

As per (International Electro technical Commission) IEC 61400-2, the definition of small turbine as having a swept area less than $200 \mathrm{~m}^{2} . .[1][2][3][4]$.

\section{Computational Fluid Dynamics}

Computational Fluid Dynamics (CFD) use to solve and analyze the problems of fluid flow . Computers use to performing the numerical calculations for simulation and the interaction of fluids like air or gases with surfaces defined by boundary conditions. CFD Permits the testing of theoretical models. With the help of Wind Tunnel Testing the CFD results can be validate by scale model or full-scale testing,CFD is a cheaper solution than wind tunnel testing. Fluent adopts multigrid solution algorithms. FLUENT uses a co-parameters are stored in the cell-center..The methods are available in Fluent are as fallows.

Pressure-based solver was developed for low-speed incompressible flows and Density-based solver was created for the high-speed compressible flows solution

The aerodynamic design of wind turbine rotor blade can be optimize by CFD a Straight Edge Blade and Swept Edge Blade.

CFD analysis Horizontal Axis Wind Turbine different turbulence models is

1. $\mathrm{k}-\omega$ shear stress transport (SST) turbulencemodel

2. $\mathrm{k}-\varepsilon$ turbulence model

3. Spalart-Allmaras

$[4,5,6,7,8]$

\section{Numerical solution}

The Geometrical model of Rotor Blade was constructed using Software CATIA as shown in fig.1.[9] [10]

The blade geometry of Micro Wind Turbine constructed using CATIA as shown in Fig. 1.The New designed airfoil AFN 2016 profile use to create turbine rotor model [12]. The CFD Analysis were made using ANSYS 16.2 Workbench.

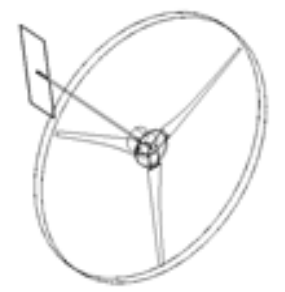

Fig. 1. Geometry of Micro Wind Turbine

A full model of turbine Rotor requires meshing at the blade surface. The interior mesh region including the wind turbine blade and the external region excluding the rectangle.Mesh size of 4-2 mm used for meshing wind turbine. 
Wall function was used to define flow characteristic in this region. ANSYS Workbench implements the automatic wall function.

For Inlet and outlet Boundary conditions, velocity conditions with turbulence intensity applied where flow enter the cylindrical domain and ambient pressure condition applied at which flows leaves, moving wall with no-slip.

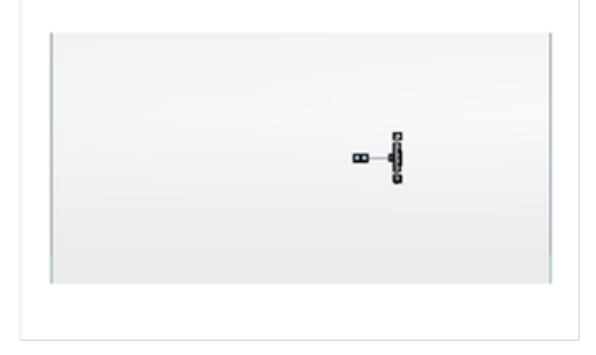

Fig. 2.Wind Turbine in Cylindrical Domain

The cylindrical domain created to wind turbine at set at center of domain of radius $1 \mathrm{~L}$ and length $5 \mathrm{~L}$ ( $\mathrm{L}=$ Turbine radius). A model was constructed as shown in Fig. 2. The air inside and around it, is named as the moving zone and was set as rotational objects in boundary conditions. The Semi-Implicit Method for Pressure-Link Equations (SIMPLE) algorithm and the standard K-E- turbulence SST model were used to simulate the incompressible, steady-state turbulent flow. The numerical simulations were conducted to model the performance of the Micro Wind Turbine under Seven different Wind speeds ranges from 3-7 $\mathrm{m} / \mathrm{s}$. with the aerodynamics equations stated in Section CFD Meshing tool. Inflation layer was applied over blade surface with sufficient resolution for the $k-\varepsilon$ turbulence model interpolating with standard pressure and density, air as fluid material. The CFD simulation was operated using ANSYS- Fluent, volume was created as the computational domain with its six faces treated to be the boundaries of the domain.

After the velocity input to the wind turbine, rotor start rotating and the power is, which will be summarisedwith the help of pre-processor Velocity and Pressure plots. The addition of the total forces, i.e. viscous and pressure forces, will give torque on the rotating structure which is produced due to the wind velocity at the rotating wall. Velocity streamlines plots and pressure contours will be plot as per change in velocity varying from $3-9 \mathrm{~m} / \mathrm{s}$.[11]

Power has been obtained as a product of and angular velocity. As shown in equation 3. Air velocities are be compared for predicting the rotor power. Torque on the rotating wall and Power generated will be calculated by,

$$
\mathrm{P}=(2 \pi \mathrm{NT}) / 60
$$

Where,P is power generated (Watt), $\mathrm{N}$ is the speed of turbine (rpm)[14,15,16].

\section{RESULT ANALYSIS}

For Input velocity of air $\mathbf{- 3 ~} \mathbf{~ m} / \mathrm{s}$

Torque on the rotating wall $-0.77 \mathrm{~N}-\mathrm{m}$

$P=(2 \times \pi \times N \times T) / 60$

$P=23.04 \mathrm{~W}$ 


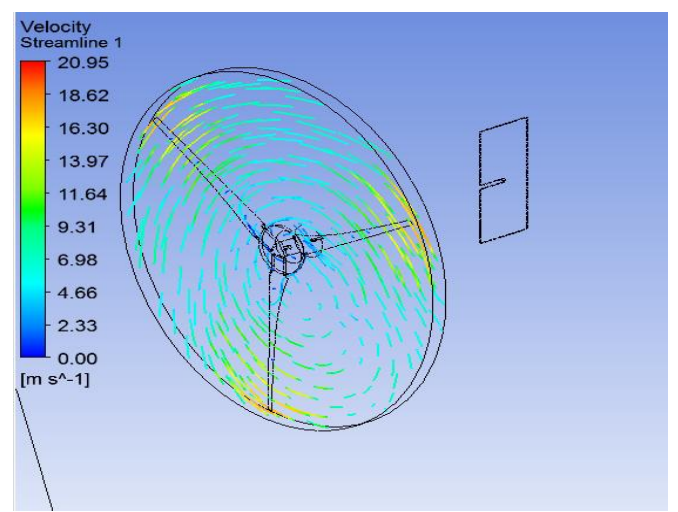

Fig. 4.Velocity streamline at $3 \mathrm{~m} / \mathrm{s}-172 \mathrm{rpm}$

$\begin{array}{lll}\text { Pressure } & \text { Uiscous } & \text { Total } \\ 1.2331575 & 0.048832863 & 1.2819904 \\ -1.2331575 & 0.048832863 & 1.2819904\end{array}$

Fig. 4, 5 and 6 shows the velocity streamline, pressure plot and velocity plot respectively

From the values obtained power developed by wind turbine calculated from equation no. 3 for different wind speed ranges from $3-9 \mathrm{~m} / \mathrm{s}$ at minimum wind speed $3 \mathrm{~m} / \mathrm{s}$ the power generated by the wind turbine is 23.04 watt at $172 \mathrm{rpm}$.

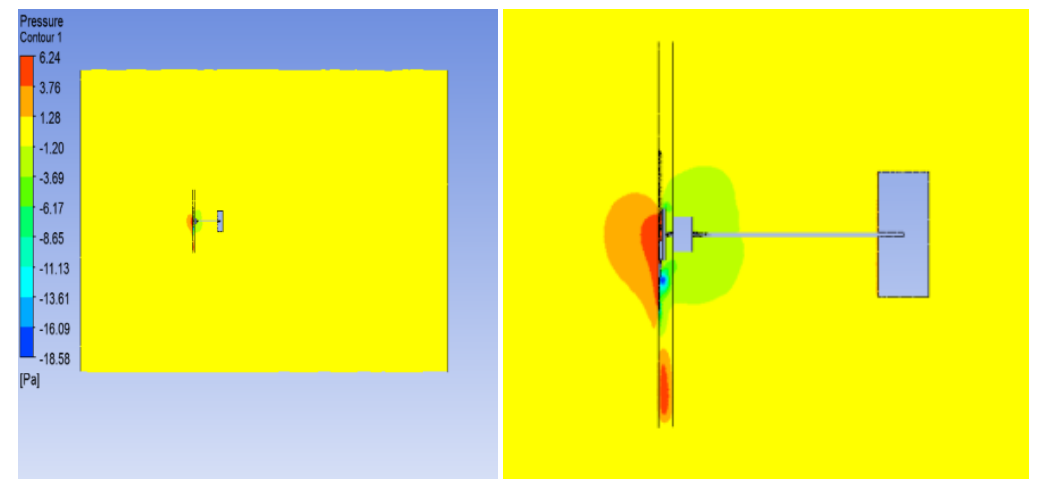

Fig. 5.Pressure Plot at section $3 \mathrm{~m} / \mathrm{s} 172 \mathrm{rpm}$

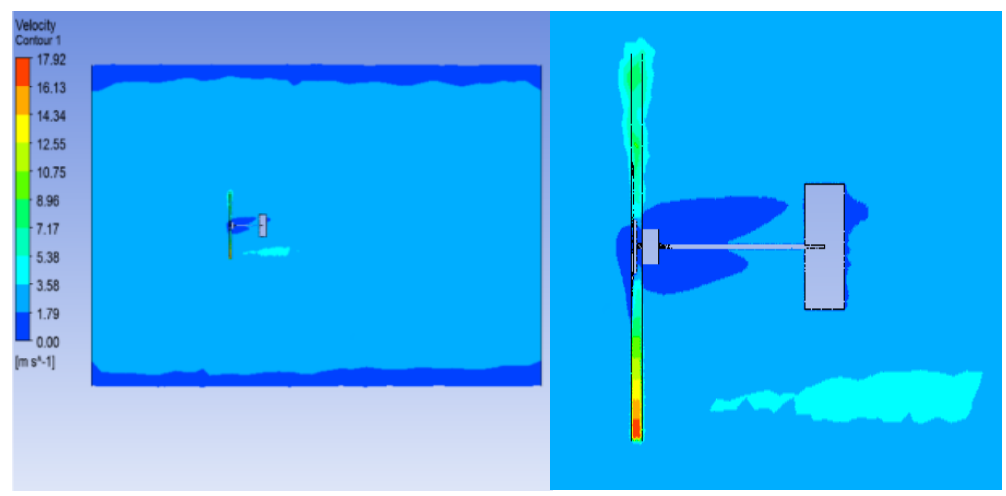

Fig. 6.Velocity plot -3 m/s- 172 rpm 


\section{A) Torque and Power Characteristics of Micro Wind Turbine}

From the CFD analysis following results wereobtained.CFD simulation was carried out for different wind speed and performance parameter namely, Torque and Power were obtained as shown in Table 1. The power output obtained at wind speed from $6 \mathrm{~m} / \mathrm{s}$ to $9 \mathrm{~m} / \mathrm{s}$ wind speed linearly. Rotor performance for the Micro Wind Turbine design variants presented in Table 1 is presented to quantify their power and torque characteristics.

TABLE 1

TORQUE AND POWER CHARACTERISTICS MICRO WIND TURBINE (CFD)

\begin{tabular}{|c|c|c|c|c|}
\hline $\begin{array}{l}\text { Wind } \\
\text { Speed } \\
(\mathbf{m} / \mathbf{s})\end{array}$ & RPM & $\begin{array}{l}\text { Rotation } \\
(\mathbf{r a d} / \mathbf{s e c})\end{array}$ & $\begin{array}{l}\text { Torque } \\
\text { Output } \\
(\mathbf{N}-\mathbf{m})\end{array}$ & $\begin{array}{l}\text { Power } \\
\text { Output }(\mathbf{W})\end{array}$ \\
\hline 3 & 172 & 18.01 & 0.77 & 23.04 \\
\hline 4 & 229 & 23.98 & 1.36 & 63.99 \\
\hline 5 & 287 & 30.05 & 3.57 & 107.27 \\
\hline 6 & 344 & 36.02 & 3.07 & 110.54 \\
\hline 7 & 401 & 41.99 & 4.16 & 174.60 \\
\hline 8 & 459 & 48.07 & 5.46 & 262.30 \\
\hline 9 & 516 & 54.04 & 6.90 & 372.65 \\
\hline
\end{tabular}

\section{B) Performance Testing Of Micro Wind Turbine}

Table 2, presents the experimental results on the relationship between the power obtained and the wind speed of the wind turbine at the wind from 3-9 m/s. Characteristic power performance curve has been presented in linear nature.

TABLE 2

\section{DATA COLLECTED FOR PERFORMANCES TEST OF MICRO WIND TURBINE}

\begin{tabular}{|c|c|}
\hline Wind speed $(\mathrm{m} / \mathrm{s})$ & Power (Watts) \\
\hline 3.0 & 8.67 \\
\hline 4.0 & 25.87 \\
\hline 5.0 & 89.78 \\
\hline 6.0 & 102.33 \\
\hline 7.0 & 171.4 \\
\hline 8.0 & 257.67 \\
\hline 9.0 & 340.64 \\
\hline
\end{tabular}




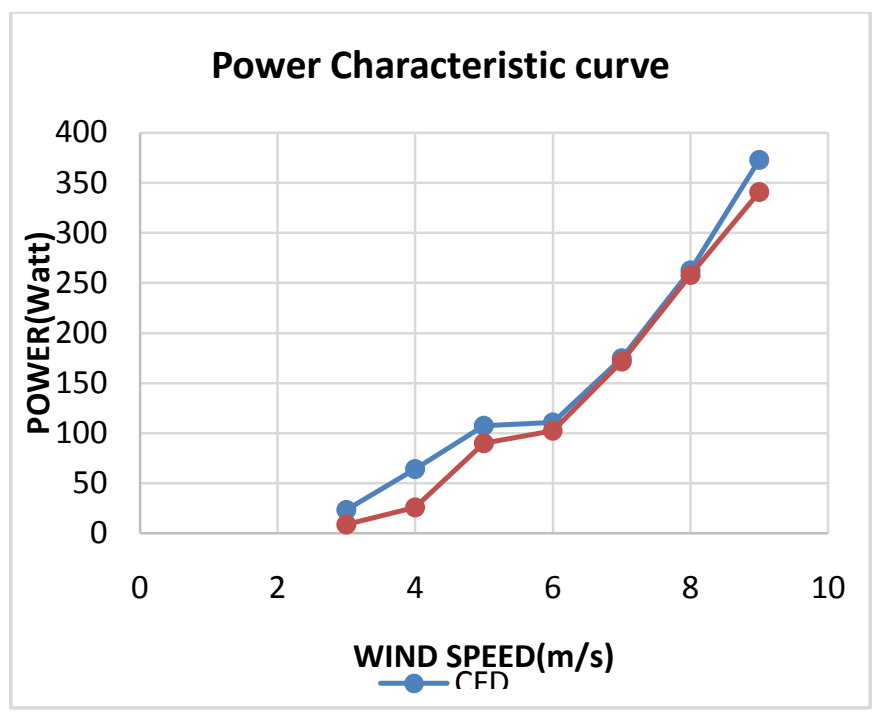

Fig.7. Comparison of Power between Experimental and CFD

Fig.7. presents the comparison of the CFD and experimental results on the relationship between the power generated by Micro Wind Turbine and the wind speed for complete rotation ranges from 3-9 m/s. It is seen that the power of wind turbine increasing gradually with increases the wind speed. This shows the experimental results match well with the CFD simulation results.

\section{CONCLUSION}

ANSYS FLUENT Workbench shows the good performance over experimental data for low wind speed, the experimental data has been used in the validation process where it indicates that the Fluent package can be used to successfully predict the performances of a Micro Wind Turbine. CFD method to be usedas an economic alternative to wind tunnel and field experimentation. CFD simulation results are observed at $9 \mathrm{~m} / \mathrm{s}$ wind velocity, the power output is 372.65 watt. From the Experimental result, Power output is calculated for wind speed $9 \mathrm{~m} / \mathrm{s}$ is obtained 340.64 watts. Energy capture is possible even at low wind speed that is cut in wind speed $3 \mathrm{~m} / \mathrm{s}$

\section{References}

[1] Manwell J F, McGowan JG, Rogers AL. Aerodynamics of wind turbines. In Wind energy explained theory, design and application. New York: Wiley (2002).

[2] Burton T , Sharpe D, Jenkins N, Bossanyi E, Aerodynamics of horizontal-axis wind turbines. In: Wind energy handbook. New York: Wiley; pp. 41-92 (2001)

[3] A.J. Vitale \& A.P. Ross, Computational method for the design of wind turbine blades, International journal of hydrogen energy 33, pp.3466 - 3470 (2008)

[4] R.S. Amano, R.J. Malloy,.CFD Analysis on Aerodynamic Design Optimization of Wind Turbine Rotor Blades, World Academy of Science, Engineering and Technology 60.( 2009)

[5] E. P. N. Duque, C. P. van Dam and S. C. Hughes, Navier-Stokes simulations of the NREL combined experiment phase II rotor, AIAA Paper, 99-0037 (1999).

[6] G. Xu and L. N. Sankar, Computational study of horizontal axis wind turbines, Journal of Solar Energy Eng, 122 (1) 35-39. (2000)

[7] N. N. Sorensen and M. O. L. Hansen, Rotor performance predictions using a Navier-Stokes method, AIAA Paper, 98- 0025 (1998). 
[8] N. N. Sorensen and J. A. Michelsen, Aerodynamic predictions for the unsteady aerodynamics experiment Phase II rotor at the national renewable energy laboratory, AIAA Paper, (2000).

[9] CATIAV5 USER GUIDE

[10] CATIA V5 Dassault's SYSTEM

[11] ANSYS16.2 WORKBENCH

[12] Sanjay. D. Nikhade, Suhas C. Kongareand Sandip A. Kale. Design of an Airfoil for Low Wind Horizontal Axis Micro Wind Turbine, 2nd International Conference for Convergence in Technology (I2CT) Siddhant College of Engineering, Pune , India. Apr 7-9, (2017)

[13] ANSYS FLUENT Theory Guide 171-188

[14]C. A. J. Fletcher. Computational Techniques for Fluid Dynamics 1.SpringerVerlag; Berlin, (1991).

[15] D.Y.C. Leung, Y. Deng, M.K.H. Leung, Design Optimization of a Cost-Effective Micro Wind Turbine , Proceedings of the World Congress on Engineering 2010 Vol II WCE 2010.

[16]. Lu Qunfeng, CHEN Jin, CHENG Jiangtao, QIN Ning, Louis Angelo M. Danao, 'Study of CFD

Simulation of a 3D Wind Turbine' IEEE( 2011). 